\title{
Characterization, Microbial Community Structure, and Pathogen Occurrence in Urban Faucet Biofilms in South China
}

\author{
Huirong Lin, Shuting Zhang, Song Gong, Shenghua Zhang, and Xin Yu \\ Institute of Urban Environment, Chinese Academy of Science, Xiamen 361021, China \\ Correspondence should be addressed to Xin Yu; xyu@iue.ac.cn
}

Received 1 July 2014; Revised 16 December 2014; Accepted 27 January 2015

Academic Editor: George Tsiamis

Copyright ( 2015 Huirong Lin et al. This is an open access article distributed under the Creative Commons Attribution License, which permits unrestricted use, distribution, and reproduction in any medium, provided the original work is properly cited.

\begin{abstract}
The composition and microbial community structure of the drinking water system biofilms were investigated using microstructure analysis and 454 pyrosequencing technique in Xiamen city, southeast of China. SEM (scanning electron microscope) results showed different features of biofilm morphology in different fields of PVC pipe. Extracellular matrix material and sparse populations of bacteria (mainly rod-shaped and coccoid) were observed. CLSM (confocal laser scanning microscope) revealed different distributions of attached cells, extracellular proteins, $\alpha$-polysaccharides, and $\beta$-polysaccharides. The biofilms had complex bacterial compositions. Differences in bacteria diversity and composition from different tap materials and ages were observed. Proteobacteria was the common and predominant group in all biofilms samples. Some potential pathogens (Legionellales, Enterobacteriales, Chromatiales, and Pseudomonadales) and corrosive microorganisms were also found in the biofilms. This study provides the information of characterization and visualization of the drinking water biofilms matrix, as well as the microbial community structure and opportunistic pathogens occurrence.
\end{abstract}

\section{Introduction}

During the past decades, scientists have paid great attention to the biofilms formation in drinking water distribution systems (DWDSs) since biofilms formation and its resistance to disinfection were considered to be potential risk in DWDSs [1-3]. Bacteria can grow in bulk water and become attached to pipe walls as biofilms. Biofilms formation in DWDSs can lead to public health issues, such as protecting pathogenic bacterial regrowth, and depletion of disinfectant [4-6]. The microbial quality of tap water is closely related to consumers' health. Thus, knowledge of biofilms behavior in DWDSs and faucet can contribute to the design of effective control strategies.

DWDSs are engineered environments that are subject to frequent, variable disturbances caused by many factors including long residence times, each associated with loss of disinfectant residual and generating higher levels of biofilms growth. These changes are reflected in the new phenotypic characteristics developed by biofilm bacteria and occurred in response to a variety of environmental signals. Phylogenetically diverse bacterial groups can inhabit the biofilms attached to the pipes and the bulk water. The study of bacterial ecology can improve the understanding of the persistence of biofilms and pathogens.

Studies to date suggest that the planktonic-biofilm transition is a complex and highly regulated process. Several methods including culture-based and independent analyses showed that members of the class Proteobacteria, including the Alpha-, Beta-, and Gammaproteobacteria were considered to be the most predominant bacterial groups in water distribution systems [7]. Recent genetic and molecular approaches used to study bacterial and fungal biofilms have identified genes and regulatory circuits important for initial cell-surface interactions, biofilm maturation, and the return of biofilm microorganisms to a planktonic mode of growth $[1,3,7]$. However, the characterization of microbial communities of biofilms in DWDSs is far from being fully understood. To give insight into the characterization and bacterial diversity of biofilms in drinking water distribution systems, microstructure analysis (SEM, CLSM and XRF) was used for the characterization of biofilms on faucet. The bacterial community compositions of real biofilms from 
TABLE 1: The biofilms samples used in this study and water quality parameters at each sampling location.

\begin{tabular}{|c|c|c|c|c|c|c|c|c|c|c|c|c|}
\hline Samples & $\mathrm{A} 1$ & $\mathrm{~A} 2$ & $\mathrm{~A} 3$ & A4 & A5 & A6 & A7 & A8 & A9 & A10 & A11 & A12 \\
\hline Tap material & $\begin{array}{c}\text { Stainless } \\
\text { steel }\end{array}$ & PVC & $\begin{array}{c}\text { Stainless } \\
\text { steel }\end{array}$ & Cast iron & Cast iron & $\begin{array}{c}\text { Stainless } \\
\text { steel }\end{array}$ & $\begin{array}{c}\text { Stainless } \\
\text { steel }\end{array}$ & Cast iron & $\begin{array}{l}\text { Cast } \\
\text { iron }\end{array}$ & $\begin{array}{c}\text { Stainless } \\
\text { steel }\end{array}$ & PVC & PVC \\
\hline Age (year) & 2 & 1 & 4 & 9 & 8 & 3 & 5 & 12 & 15 & 6 & 1 & 0.5 \\
\hline $\mathrm{pH}$ & 7.08 & 6.8 & 7.01 & 6.62 & 7.11 & 7.03 & 6.94 & 7.35 & 7.26 & 6.83 & 6.98 & 6.7 \\
\hline TSS & 40 & 49 & 99 & 75 & 81 & 69 & 39 & 80 & 69 & 73 & 52 & 47 \\
\hline Turbidity & 0.6 & 0.3 & 0.3 & 0.2 & 0.4 & 0.2 & 0.1 & 0.3 & 0.2 & 0.1 & 0.4 & 0.3 \\
\hline $\begin{array}{l}\text { Residual } \\
\text { chlorine }(\mathrm{mg} / \mathrm{L} \\
\left.\mathrm{Cl}_{2}\right)\end{array}$ & 0.55 & 0.54 & 0.62 & 0.46 & 0.49 & 0.63 & 0.65 & 0.57 & 0.61 & 0.62 & 0.3 & 0.4 \\
\hline Sulfate $(\mathrm{mg} / \mathrm{L})$ & 10.4 & 12.9 & 31.8 & 24.2 & 30.6 & 13.8 & 24.2 & 22 & 27.8 & 19.8 & 17.8 & 16.5 \\
\hline
\end{tabular}

12 urban household taps (Xiamen, southeast of China) were detected using 454 pyrosequencing technique. Potential pathogens and corrosive microorganisms occurrence was also discussed.

\section{Methods}

2.1. Characterization and Visualization of the Biofilms Matrix in DWDSs. In order to observe the biofilms formed on drinking water pipe surface, five $5 \times 5 \mathrm{~mm}$ removable $\mathrm{PVC}$ sheets were inserted in real PVC DWDSs pipe for biofilm attachment. They were sterilized by immersion in $70 \%$ ethanol for $2 \mathrm{~min}$ individually and air dried. The PVC tap in our lab was twisted off and the sheets were transferred with sterile forceps to the tap; then, the tap was screwed on. After three months, PVC sheets were took out for scanning electron microscopy (SEM) and staining. One PVC sheet was fixed, dried, and viewed with a scanning electron microscope (Hitachi S-4800, Japan). The other four were stained with DAPI (4,6-diamidino-2-phenylindole) for attach cells, FITC (fluorescein isothiocyanate) for extracellular protein, Con-A (concanavalin A) for $\alpha$-polysaccharide, and CW (calcofluor white) for $\beta$-polysaccharide, respectively. Each kind of stain was added on each sheet in the dark. After 15 min the sheets were analyzed using CLSM. CLSM 3D-image was used to visualize the staining biofilms. The CLSM scanned different layers of the staining biofilms. The thickness of the biofilms was got from signals of different layers using the software ZEN 2008 Light Edition.

2.2. Biofilms Sampling for 454 Pyrosequencing. It is difficult to get the information on the microbial diversity of biofilms within DWDSs due to limited access and the high cost involved in sampling. In this study, biofilms in taps were collected from a drinking water distribution system of Xiamen, Fujian Province in southeast of China. Different taps with different materials and different ages were studied (Table 1). The taps were removed and ethanol-sterilized cotton swabs were then used to collect biofilms on the taps. Then, the collected biofilms were moved to $2 \mathrm{~mL}$ sterilized EP tubes and put into an ice box during transportation. For each sampling point, the physicochemical water quality parameters were measured and listed in Table 1.

2.3. X-Ray Fluorescence (XRF) Analysis of Biofilms A3 on Corroded Tap. Among the biofilms samples, A3 was red, indicating that the pipe was corroded. In order to analyze the element contents in the biofilms, XRF analysis of the biofilms A3 was performed at the XRF microprobe station (beam line 4W1B) of Beijing Synchrotron Radiation Facility (BSRF), Institute of High Energy Physics of China. The electron energy in the storage ring was $2.2 \mathrm{GeV}$, with a current range from 78 to $120 \mathrm{~mA}$. The size of the exciting X-ray beam was $10 \mu \mathrm{m} \times 20 \mu \mathrm{m}$. XRF spectra were collected by a PGY Si (Li) solid detector, positioned at $90^{\circ}$ to the beam line. The scanning point of the sample was selected and observed by a microscope.

2.4. DNA Extraction, 16S rRNA Genes Amplification, and Pyrosequencing. Total DNA of the biofilms samples was extracted and purified using a bead beating method (FastDNATMSPIN Kit for Soil, Bio101 Inc., USA) following the manufacturer's instructions. For pyrosequencing analysis, the V3 and V4 region of 16S rRNA gene was amplified with the primers $338 \mathrm{~F}\left(5^{\prime}\right.$-ACTCCTACGGGAGGCAGCAG$\left.3^{\prime}\right)$ and 802R ( $5^{\prime}$-TACNVGGGTATCTAATCC- $\left.3^{\prime}\right)$. The PCR was carried out in a total volume of $20 \mu \mathrm{L}: \mathrm{H}_{2} \mathrm{O} 13.25 \mu \mathrm{L}$, 10xPCR ExTaq Buffer $2.0 \mu \mathrm{L}$, DNA template $(100 \mathrm{ng} / \mu \mathrm{L})$ $0.5 \mu \mathrm{L}$, primer $338 \mathrm{~F}(10 \mathrm{mmol} / \mathrm{L}) 1.0 \mu \mathrm{L}, 802 \mathrm{R}(10 \mathrm{mmol} / \mathrm{L})$ $1.0 \mu \mathrm{L}$, dNTP $2.0 \mu \mathrm{L}$, and ExTaq $(5 \mathrm{U} / \mathrm{mL}) 0.25 \mu \mathrm{L}$. The DNA amplification condition used in this study was initial denaturation at $95^{\circ} \mathrm{C}$ for $3 \mathrm{~min}$, followed by 35 cycles of $10 \mathrm{~s}$ at $95^{\circ} \mathrm{C}$, $30 \mathrm{~s}$ at $58^{\circ} \mathrm{C}$, and $6 \mathrm{sec}$ at $72^{\circ} \mathrm{C}$, followed by a final extension at $72^{\circ} \mathrm{C}$ for $7 \mathrm{~min}$. The PCR products were purified and endrepaired, A-tailed, PE-adapter ligated, and then utilized for pyrosequencing on the 454 Genome Sequencer FLX platform [8].

The unique tags (nonredundant tags) were obtained and aligned against the $16 \mathrm{~S}$ rRNA database using the BLASTN algorithm. The raw sequences obtained from 454 pyrosequencing were optimized. The redundant tags were deleted by Mothur v.1.11.0 [9]. Sequences with similarities greater than 
97\% were grouped in one OTU. Using the MEGA5.0 program, the 60 bp representative sequences were aligned by the ClustalW with default settings, and a phylogenetic analysis was performed based on the neighbor-joining method [9].

\section{Results and Discussion}

3.1. Characterization and Visualization of the Drinking Water Biofilms Matrix. DWDSs are engineered environments which are subject to frequent, variable disturbances caused by many factors including long residence times due to dead ends and low flow rates, and the latter are associated with loss of disinfectant residual and generating higher levels of biofilm growth. Attachment is required for biofilms formation, and bacteria interact with pipe wall surface through adhesions including polysaccharides and surface proteins, with initial contact often mediated by active motility. The formation of a biofilm is the result of successional development into a mature community, which may require several years before steady state is achieved. For example, it was found that the successional development of a model DW biofilm during a 3-year period was an orderly process resulting in a stable, well-defined community [10]. In order to observe and characterize a real DWDSs biofilm, CLSM and SEM were applied in this study. SEM analysis of the PVC slice revealed different features of biofilms morphology in different fields of the PVC pipe surface. Possible EPS was present on the PVC slice in one field (Figures 1(a) and 1(b)). Sparse populations of mainly rod-shaped bacteria were observed in another field (Figure 1(c)). There were also globular-shaped bacteria (Figure 1(d)). Using Zen 2008 software, the "range" value showed the thickness of the biofilm. CLSM 3D-image results suggested that after three months' growth the biofilm was about $20 \mu \mathrm{m}$ thick. CLSM results also revealed different distributions of attached cells (Figure 1(e)), extracellular protein (Figure 1(f)), $\alpha$-polysaccharide (Figure 1(g)), and $\beta$ polysaccharide (Figure 1(h)).

During sampling, it was found that there were some yellow iron filings in the biofilm A3, suggesting that the Fe in the stainless steel pipe was released. In order to obtain the elements contents of corroded biofilm A3, XRF was used. Figure 2 was the typical spot scan result of biofilm A3. It showed that $\mathrm{K}, \mathrm{Ca}, \mathrm{Fe}, \mathrm{Cu}$, and $\mathrm{Zn}$ were present in biofilm $\mathrm{A} 3$, suggesting that this pipe was corroded and metal elements were released which might affect the water quality in the DWDSs. Our study enabled the concurrent visualization and evaluation of the biofilm growth as well as EPS matrix (extracellular proteins and polysaccharide).

3.2. Diversity of Microbial Communities in the Tap Biofilms. Pyrosequencing is a powerful tool to investigate microorganisms community [11]. Compared with conventional cloning and sequencing methods, pyrosequencing can obtain more sequences and OTUs. In this study, 8 biofilms samples were successfully high-throughput pyrosequenced among the 12 samples. To assess the sequencing depth and the species richness, a rare faction curve was constructed for each sample. Alpha diversity measurement for the samples (Table 2) suggested variations in species richness (Chaol) and species evenness (Simpson index) among different biofilms samples. Higher species richness of a given sample might present a lower species diversity resulting from a lower evenness of the sample. PcoA results indicated that the biofilms samples obtained from different tap materials showed quite different clusters. Biofilms formed on PVC had a more simple microbial community compared with those formed on cast iron and stainless steel. This result was consistent with another study which conducted with $16 \mathrm{~S}$ rRNA genes sequence [12]. These results indicated that PVC was a more ideal material compared with the other materials as fewer bacteria attached on it.

3.3. Composition of Microbial Community. DWDSs biofilms are considered to be complex, dynamic microbial assemblages with extensive phenotypic diversity supporting adaptation to different hydraulic and chemical surface conditions $[3,13-15]$. As a result, biofilms formed on different materials might have different community structures. The phylogenetic analysis based on the 16S rRNA V3-V4 region sequences from the biofilms samples was showed in Figure 3. The points in this figure were dispersive. It suggested that distinct bacterial communities were detected in these biofilms from different tap materials and different ages. Many factors could influence the bacterial communities including pipe age and pipe material. However, some interesting information could be found. For example, A8 and A9 (biofilms formed on cast iron) located in one region, while $\mathrm{A} 1$ and $\mathrm{A} 3$ (biofilms formed on stainless steel) located in another region. This result suggested that the pipe materials might be an important factor for the bacterial communities of the biofilms. In addition, biofilms A2 formed on PVC had relatively simple bacterial community structure, with Betaproteobacteria (54.09\%) and Alphaproteobacteria (38.24\%) as its main community composition (Figure 4). It was quite different from the biofilms formed on cast iron and stainless steel.

The bacterial communities of the samples in both class and species were shown in Figure 4. A high variability of the bacterial core communities of the biofilms was found in this study. Taxonomic analysis revealed that proteobacteria was the common and predominant group in all biofilms samples. These results were broadly consistent with other biofilms studies $[7,16]$. Besides, Actinobacteria was the second largest bacterial group in the samples A2, A8, A9, and A10. Some important bacteria should be paid attention to. For example, Sphingomonadales was found in all samples. This might be due to the resistance to chlorine of Sphingomonadales. In addition, Nitrospiraceae and Thiotrichales were found in this study, suggesting the occurrence of nitrification and sulfur transformation.

3.4. Potential Pathogen and Corrosive Microorganisms Occurrence. Opportunistic pathogens in drinking water systems are an emerging health concern. In this study, some waterborne opportunistic pathogens were found in the biofilms 


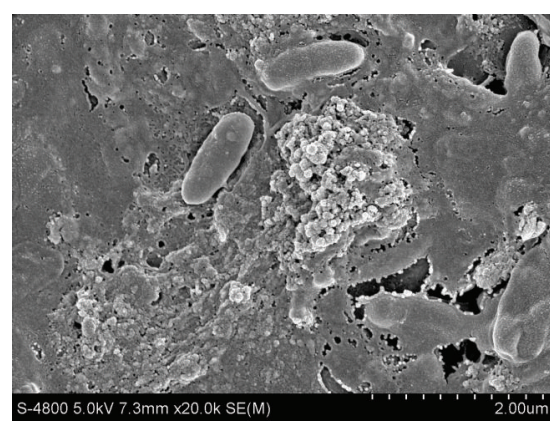

(a)

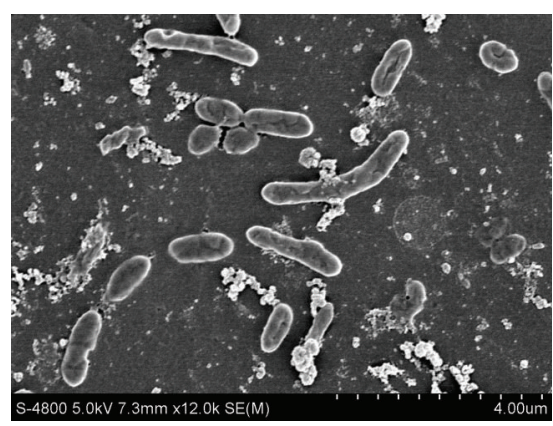

(c)

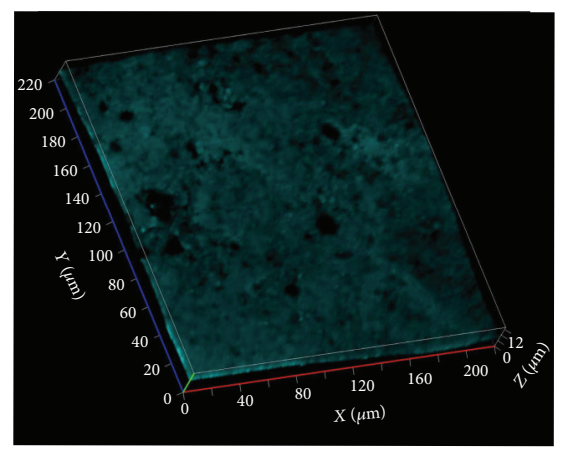

(e)

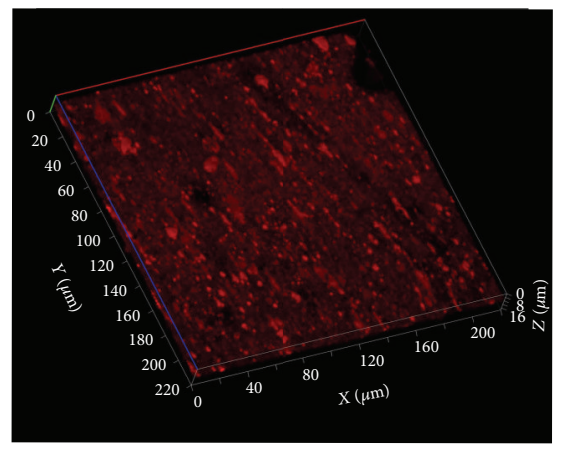

(g)

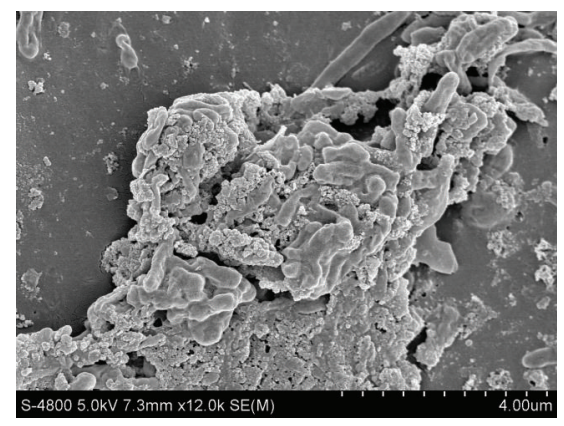

(b)

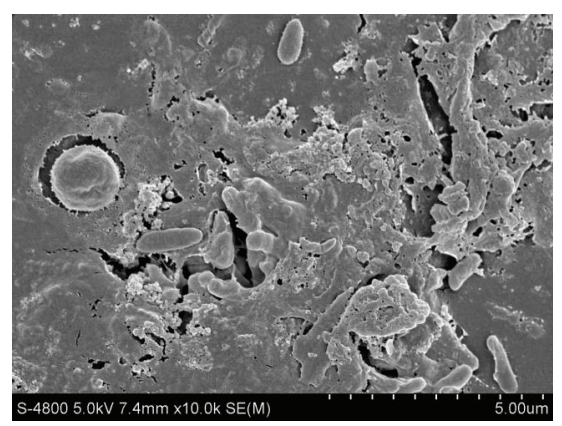

(d)

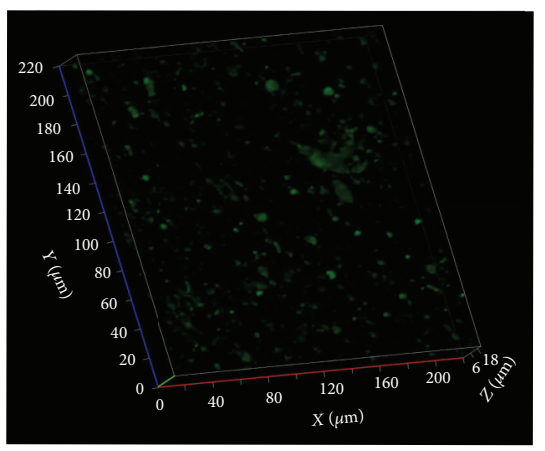

(f)

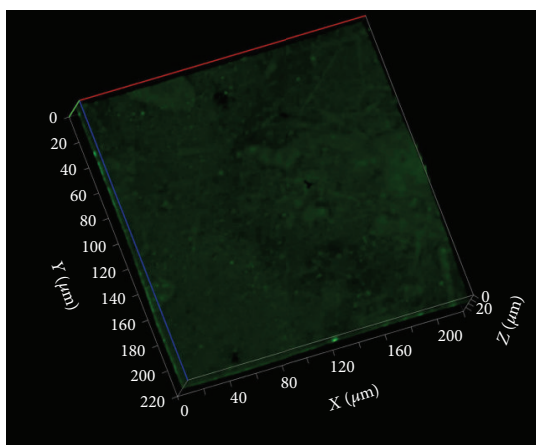

(h)

FIgURE 1: Visualization of the drinking water biofilms matrix on the PVC slice after three months growth. SEM images of extracellular matrix material (a, b) and rod-shaped bacteria (c) and globular-shaped bacteria (d), CLSM 3D-image of staining biofilms on the surface of the PVC slice after three months growth, DAPI for attach cells (e), FITC for extracellular protein (f), Con-A for $\alpha$-polysaccharide (g), and CW for $\beta$-polysaccharide (h). 
TABLE 2: Comparison of phylotype coverage and diversity estimators of the microbial community structure employing the 454 pyrosequencing analysis.

\begin{tabular}{|c|c|c|c|c|c|c|c|}
\hline Tap material & Samples & Reads & OTUs & $\mathrm{ACE}$ & Chao 1 & Shannon & Simpson \\
\hline PVC & A2 & 10,804 & 81 & 129 & 139 & 3.64 & 0.862 \\
\hline \multirow{4}{*}{ Stainless steel } & $\mathrm{A} 1$ & 9,826 & 186 & 298 & 292 & 4.63 & 0.898 \\
\hline & A3 & 36,655 & 146 & 294 & 276 & 3.93 & 0.888 \\
\hline & A7 & 14,605 & 114 & 204 & 202 & 4.08 & 0.896 \\
\hline & A10 & 9,826 & 351 & 478 & 481 & 5.37 & 0.927 \\
\hline \multirow{3}{*}{ Cast iron } & A5 & 13,660 & 106 & 182 & 192 & 3.27 & 0.831 \\
\hline & A8 & 13,214 & 217 & 383 & 340 & 4.43 & 0.921 \\
\hline & A9 & 27,517 & 152 & 250 & 256 & 4.46 & 0.916 \\
\hline
\end{tabular}

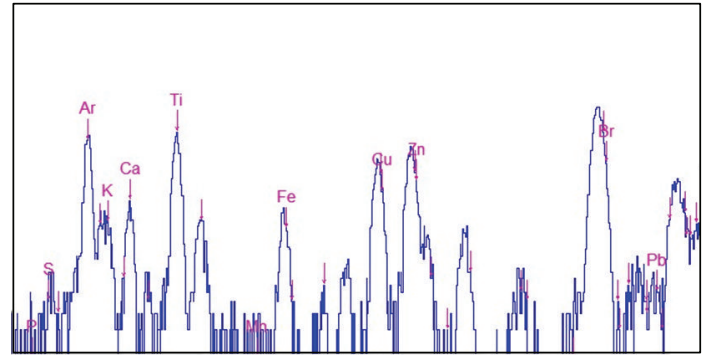

FIGURE 2: Typical XRF spectra in biofilm A3 from drinking water distribution stainless steel pipe wall. The Ar peak was from the air, while $\mathrm{Ti}$ and $\mathrm{Br}$ peak were artefact caused by $3 \mathrm{M}$ tape for fixing sample.

samples. They were members of species Legionellales, Enterobacteriales, Chromatiales, Pseudomonadales, and Enterococcaceae, although there were differences in numbers for each sample. Abundance of some potential corrosive microorganisms and pathogens in genus level in different bacterial communities was listed in Table 3 . These pathogen bacteria in the biofilms may be the risk to human health and lead to clinical and outbreak cases. In previous studies, it was found that environmental pathogens such as Legionella pneumophila and Mycobacterium avium have been shown to be associated with DW biofilms $[1,17,18]$. Our taxonomic findings are consistent with these studies. In some studies, it was found that Mycobacteria were found to be the predominant bacterial genera in DWDSs because they were generally resistant to disinfectants due to their complex cell wall $[3,18-$ 20]. However, it was not detected in this study.

As corrosion was found in the biofilm A3 and XRF result showed high $\mathrm{Fe}, \mathrm{Cu}$, and $\mathrm{Pb}$ contents in the biofilms sample, the bacterial community information was further analyzed to understand the possible roles of microorganisms in iron corrosion. Thiotrichales (sulfur oxiding bacteria) was found in A1 biofilm sample form on stainless steel. In addition, potential iron reducing bacteria (Bacillales, Clostridiales, and Pseudomonadales) were found in some samples (Table 3). It was reported that IRB might generate $\mathrm{Fe}_{3} \mathrm{O}_{4}$ in anaerobic conditions, leading to corrosion in DWDSs. As a key impact factor to corrosion, the sulfate contents in the drinking

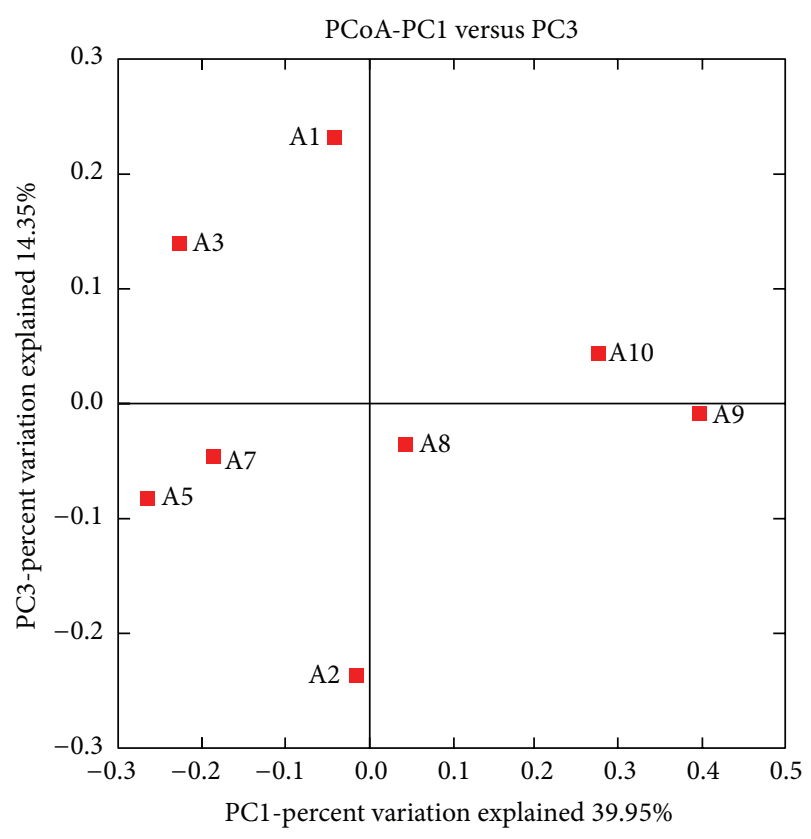

FIGURE 3: Phylogenetic analysis based on the $16 \mathrm{~S}$ rRNA V3-V4 region sequences from the biofilms samples.

water of this city are usually low according to the general survey. For example, survey data in 2012 showed that there were among the 102 samples, only 2 samples had the sulfate contents higher than $30 \mathrm{mg} / \mathrm{L}$. So in this study, fewer corrosive microorganisms were found in this city, compared with another study which was conducted on the biofilms with higher sulfate contents in water [21]. Nevertheless, these corrosive microorganisms might contribute to corrosion of drinking water pipes. It should be noticed that the genus members within the genera Bacillus and Clostridium could affect iron corrosion and modify the corrosion products [22].

\section{Conclusions}

In this study, combined use of SEM, CLSM, and XRF was successfully conducted for the characterization and visualization of the drinking water biofilms matrix. EPS and 


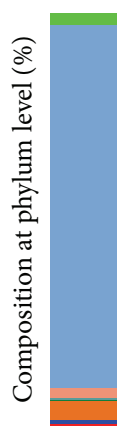

A1

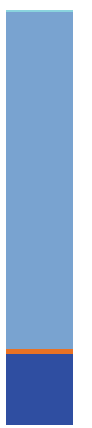

A2

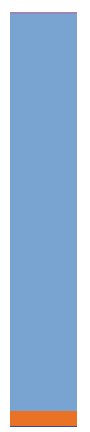

A3

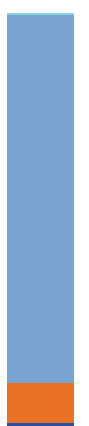

A5

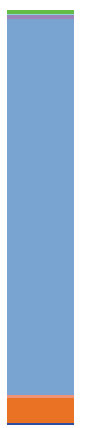

A7

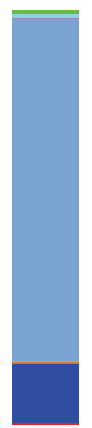

A8

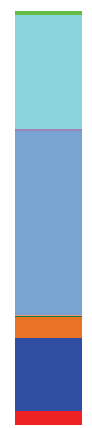

A9

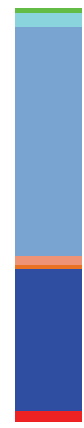

A10

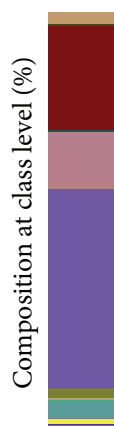

A1

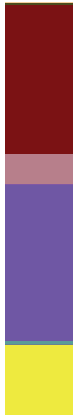

A2

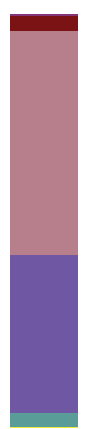

A3

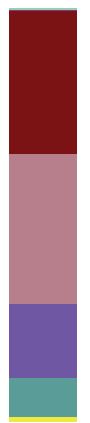

A5

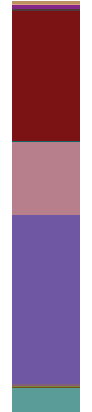

Samples

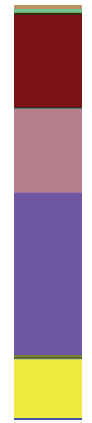

A8

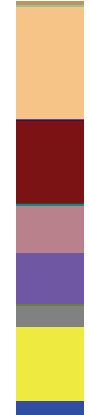

A9

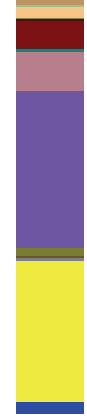

A10

Bacteria; Acidobacteria; Acidobacteria_Gp16

Bacteria; Acidobacteria; Acidobacteria_Gp3

Bacteria; Acidobacteria; Acidobacteria_Gp4

Bacteria; Acidobacteria; Acidobacteria_Gp6

Bacteria; Acidobacteria; Holophagae

Bacteria; Actinobacteria; Actinobacteria

Bacteria; Bacteroidetes; Bacteroidetes_class_incertae_sedis

Bacteria; Bacteroidetes; Bacteroidia

Bacteria; Bacteroidetes; Sphingobacteria

Bacteria; Bacteroidetes; Flavobacteria

Bacteria; Bacteroidetes; Other

Bacteria; Chlamydiae; Chlamydiae

Bacteria; Chloroflexi; Thermomicrobia

Bacteria; Deinococcus-Thermus; Deinococci

Bacteria; Fusobacteria; Fusobacteria

Bacteria; Gemmatimonadetes; Gemmatimonadetes

- Bacteria; Nitrospira; Nitrospira

Bacteria; Planctomycetes; Planctomycetacia

Bacteria; Proteobacteria; Alphaproteobacteria

Bacteria; Proteobacteria; Betaproteobacteria

Bacteria; Proteobacteria; Deltaproteobacteria

- Bacteria; Proteobacteria; Gammaproteobacteria

Bacteria; Proteobacteria; Other

Bacteria; Spirochaetes; Spirochaetes

Bacteria; Verrucomicrobia; Other

Bacteria; Verrucomicrobia; Spartobacteria

Bacteria; Verrucomicrobia; Subdivision3

Bacteria; Verrucomicrobia; Verrucomicrobiae

Bacteria; Firmicutes; Bacilli

Bacteria; Firmicutes; Clostridia

Bacteria; Firmicutes; Erysipelotrichia

Bacteria; ODl; ODl_class_incertae_sedis

Bacteria; Other; Other

Bacteria; TM7; TM7_class_incertae_sedis

(b)

Figure 4: Proportional composition of microbes in the biofilms samples on different materials and from different ages at the phylum level (a) and class level (b). The information of each biofilm sample was listed in Table 1.

bacteria (mainly rod-shaped and coccoid) were observed in the biofilms. Four hundred fifty-four pyrosequencing used to characterize bacterial diversity in these biofilms samples suggested that there were differences in the bacterial community composition between different biofilms samples formed on different tap materials with different ages. Proteobacteria (mostly Alpha-, Beta-, and Gamma-) predominated in the biofilms samples. Some potential pathogens (members of species Legionellales, Enterobacteriales, Chromatiales, and Pseudomonadales) were found in the biofilms samples. There were also some potential corrosive microorganisms (Thiotrichales, Bacillales, Clostridiales, and Pseudomonadales). In order to prevent biofilms formation, PVC might be a more ideal material compared with the others. This work might add some new insights into microbial community and its influential factors in DWDSs. 
TABLE 3: Abundance of some potential pathogen and corrosive microorganisms in genus level in different bacterial communities (count).

\begin{tabular}{|c|c|c|c|c|c|c|c|c|c|}
\hline & \multirow{2}{*}{ genera } & \multirow{2}{*}{$\begin{array}{c}\text { PVC } \\
\text { A2 } \\
\end{array}$} & \multicolumn{4}{|c|}{ stainless steel } & \multicolumn{3}{|c|}{ cast iron } \\
\hline & & & $\mathrm{A} 1$ & A3 & A7 & A10 & A5 & A8 & A9 \\
\hline \multirow{4}{*}{ Pathogen } & Escherichia_Shigella & 1 & 0 & 1 & 0 & 0 & 0 & 1 & 0 \\
\hline & Legionella & 0 & 4 & 5 & 0 & 7 & 0 & 4 & 4 \\
\hline & Pseudomonas & 13 & 27 & 70 & 39 & 444 & 66 & 429 & 1219 \\
\hline & Enterococcus & 0 & 0 & 0 & 0 & 0 & 0 & 2 & 0 \\
\hline SOB & Thiobacillus & 0 & 7 & 0 & 0 & 0 & 0 & 0 & 0 \\
\hline \multirow{4}{*}{ IRB } & Bacillus & 0 & 0 & 2 & 1 & 382 & 0 & 1 & 1826 \\
\hline & Clostridium $X l \mathrm{Va}$ & 0 & 0 & 0 & 0 & 0 & 4 & 0 & 0 \\
\hline & Clostridium_XVIII & 0 & 0 & 0 & 0 & 0 & 0 & 1 & 0 \\
\hline & Pseudomonas & 13 & 27 & 70 & 39 & 444 & 66 & 429 & 1219 \\
\hline
\end{tabular}

SOB: sulfur oxidizing bacteria; IRB: iron reducing bacteria.

\section{Conflict of Interests}

The authors declare that there is no conflict of interests regarding the publication of this paper.

\section{Acknowledgments}

This work was supported by National High-Tech Research and Development (2012AA062607), the National Natural Science Foundation of China (31300109 and 51278482), Fujian Provincial Natural Science Foundation (2013J05087), and the Science and Technology Project of Xiamen (3502Z20132013).

\section{References}

[1] F. Emtiazi, T. Schwartz, S. M. Marten, P. Krolla-Sidenstein, and U. Obst, "Investigation of natural biofilms formed during the production of drinking water from surface water embankment filtration," Water Research, vol. 38, no. 5, pp. 1197-1206, 2004.

[2] M. Tachikawa, M. Tezuka, M. Morita, K. Isogai, and S. Okada, "Evaluation of some halogen biocides using a microbial biofilm system," Water Research, vol. 39, no. 17, pp. 4126-4132, 2005.

[3] D. Berry, C. W. Xi, and L. Raskin, "Microbial ecology of drinking water distribution systems," Current Opinion in Biotechnology, vol. 17, no. 3, pp. 297-302, 2006.

[4] M. W. LeChevallier, W. Schulz, and R. G. Lee, "Bacterial nutrients in drinking water," Applied and Environmental Microbiology, vol. 57, no. 3, pp. 857-862, 1991.

[5] C. M. Buswell, Y. M. Herlihy, L. M. Lawrence et al., "Extended survival and persistence of Campylobacter spp. in water and aquatic biofilms and their detection by immunofluorescentantibody and -rRNA staining," Applied and Environmental Microbiology, vol. 64, no. 2, pp. 733-741, 1998.

[6] J. M. Regan, G. W. Harrington, and D. R. Noguera, "Ammoniaand nitrite-oxidizing bacterial communities in a pilot-scale chloraminated drinking water distribution system," Applied and Environmental Microbiology, vol. 68, no. 1, pp. 73-81, 2002.

[7] P.-Y. Hong, C. Hwang, F. Ling, G. L. Andersen, M. W. LeChevallier, and W.-T. Liu, "Pyrosequencing analysis of bacterial biofilm communities in water meters of a drinking water distribution system," Applied and Environmental Microbiology, vol. 76, no. 16, pp. 5631-5635, 2010.
[8] P. D. Schloss, S. L. Westcott, T. Ryabin et al., "Introducing mothur: open-source, platform-independent, communitysupported software for describing and comparing microbial communities," Applied and Environmental Microbiology, vol. 75, no. 23, pp. 7537-7541, 2009.

[9] K. Tamura, D. Peterson, N. Peterson, G. Stecher, M. Nei, and S. Kumar, "MEGA5: molecular evolutionary genetics analysis using maximum likelihood, evolutionary distance, and maximum parsimony methods," Molecular Biology and Evolution, vol. 28, no. 10, pp. 2731-2739, 2011.

[10] A. C. Martiny, T. M. Jørgensen, H.-J. Albrechtsen, E. Arvin, and S. Molin, "Long-term succession of structure and diversity of a biofilm formed in a model drinking water distribution system," Applied and Environmental Microbiology, vol. 69, no. 11, pp. 6899-6907, 2003.

[11] A. Gobet, S. I. Böer, S. M. Huse et al., "Diversity and dynamics of rare and of resident bacterial populations in coastal sands," ISME Journal, vol. 6, no. 3, pp. 542-553, 2012.

[12] W. F. Lin, Z. S. Yu, X. Chen, R. Liu, and H. Zhang, "Molecular characterization of natural biofilms from household taps with different materials: PVC, stainless steel, and cast iron in drinking water distribution system," Applied Microbiology and Biotechnology, vol. 97, no. 18, pp. 8393-8401, 2013.

[13] P. Deines, R. Sekar, H. S. Jensen et al., "MUWS (Microbiology in Urban Water Systems) - an interdisciplinary approach to study microbial communities in urban water systems," in Integrating Water Systems, pp. 397-403, 2014.

[14] R. S. Roeder, J. Lenz, P. Tarne, J. Gebel, M. Exner, and U. Szewzyk, "Long-term effects of disinfectants on the community composition of drinking water biofilms," International Journal of Hygiene and Environmental Health, vol. 213, no. 3, pp. 183189, 2010.

[15] I. Douterelo, R. L. Sharpe, and J. B. Boxall, "Influence of hydraulic regimes on bacterial community structure and composition in an experimental drinking water distribution system," Water Research, vol. 47, no. 2, pp. 503-516, 2013.

[16] R. P. Revetta, V. Gomez-Alvarez, T. L. Gerke, C. Curioso, J. W. S. Domingo, and N. J. Ashbolt, "Establishment and early succession of bacterial communities in monochloraminetreated drinking water biofilms," FEMS Microbiology Ecology, vol. 86, no. 3, pp. 404-414, 2013.

[17] J. O. Falkinham, M. D. Iseman, P. de Haas, and D. van Soolingen, "Mycobacterium avium in a shower linked to pulmonary 
disease," Journal of Water and Health, vol. 6, no. 2, pp. 209-213, 2008.

[18] R. Liu, Z. Yu, H. Zhang, M. Yang, B. Shi, and X. Liu, "Diversity of bacteria and mycobacteria in biofilms of two urban drinking water distribution systems," Canadian Journal of Microbiology, vol. 58, no. 3, pp. 261-270, 2012.

[19] L. C. Simões, M. Simões, and M. J. Vieira, "Influence of the diversity of bacterial isolates from drinking water on resistance of biofilms to disinfection," Applied and Environmental Microbiology, vol. 76, no. 19, pp. 6673-6679, 2010.

[20] R. Liu, Z. Yu, H. Guo, M. Liu, H. Zhang, and M. Yang, "Pyrosequencing analysis of eukaryotic and bacterial communities in faucet biofilms," Science of the Total Environment, vol. 435-436, pp. 124-131, 2012.

[21] H. F. Sun, B. Y. Shi, Y. H. Bai, and D. Wang, "Bacterial community of biofilms developed under different water supply conditions in a distribution system," Science of the Total Environment, vol. 472, pp. 99-107, 2014.

[22] J. E. Kostka, D. D. Dalton, H. Skelton, S. Dollhopf, and J. W. Stucki, "Growth of iron (III)-reducing bacteria on clay minerals as the sole electron acceptor and comparison of growth yields on a variety of oxidized iron forms," Applied and Environmental Microbiology, vol. 68, no. 12, pp. 6256-6262, 2002. 

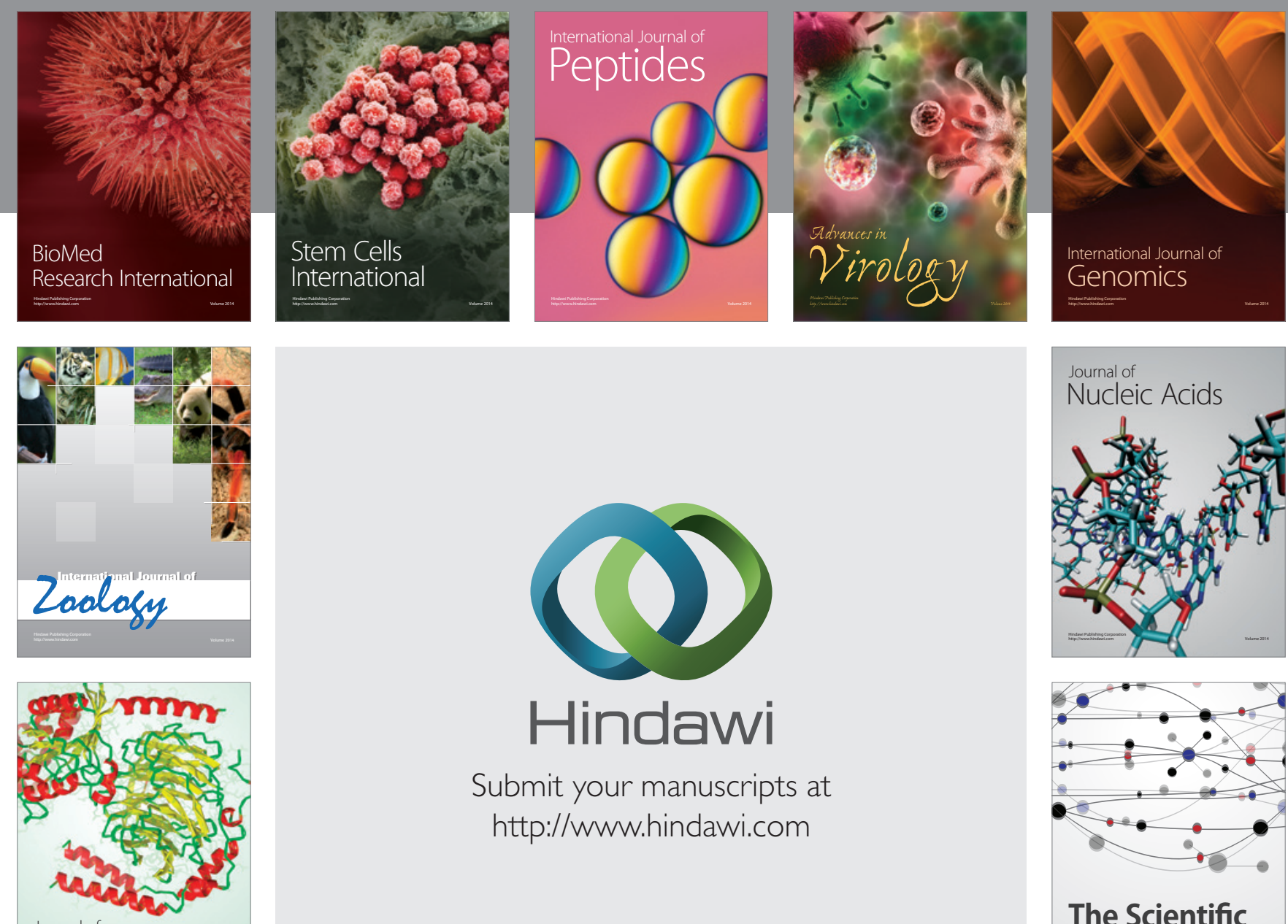

Submit your manuscripts at

http://www.hindawi.com

Journal of
Signal Transduction
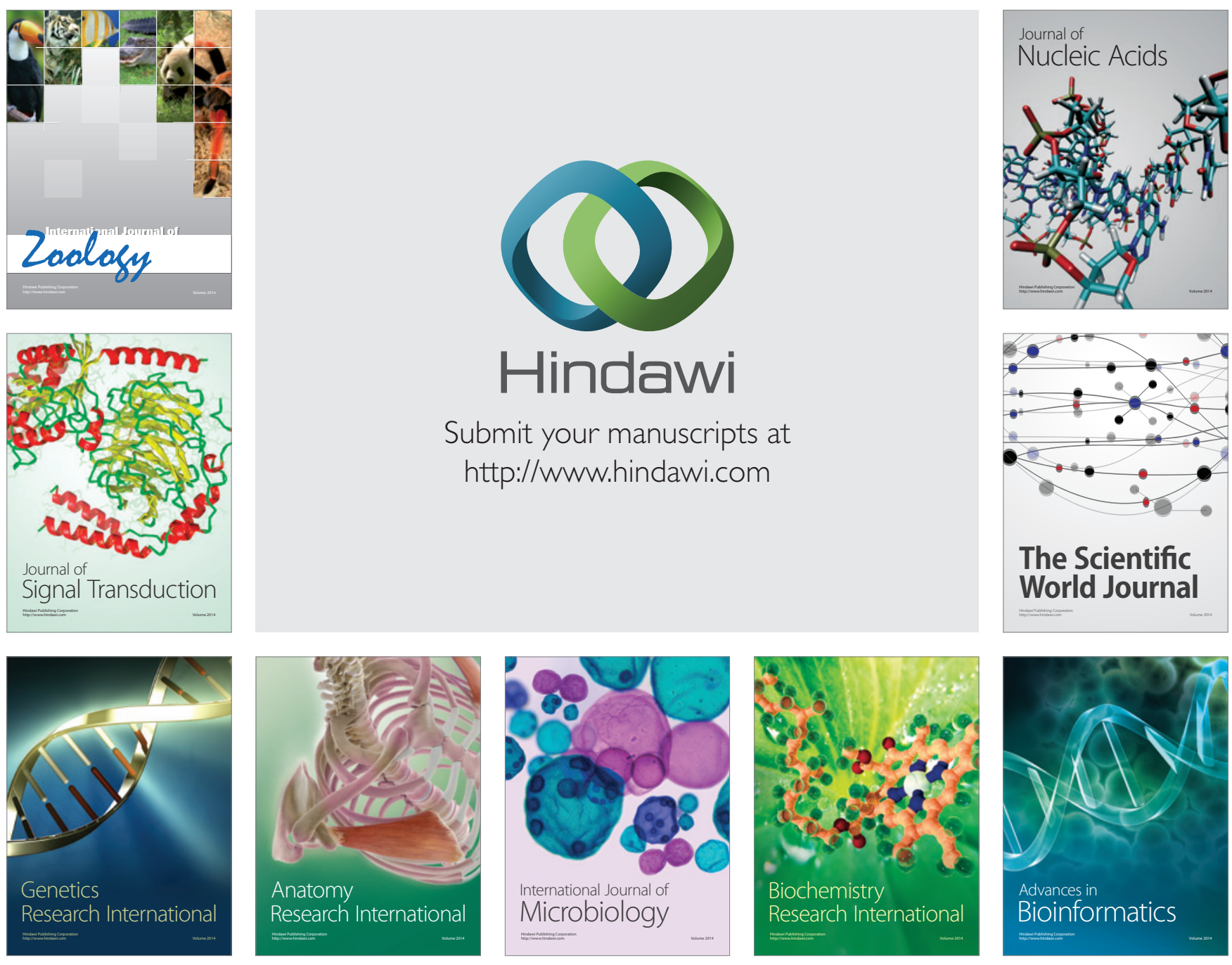

The Scientific World Journal
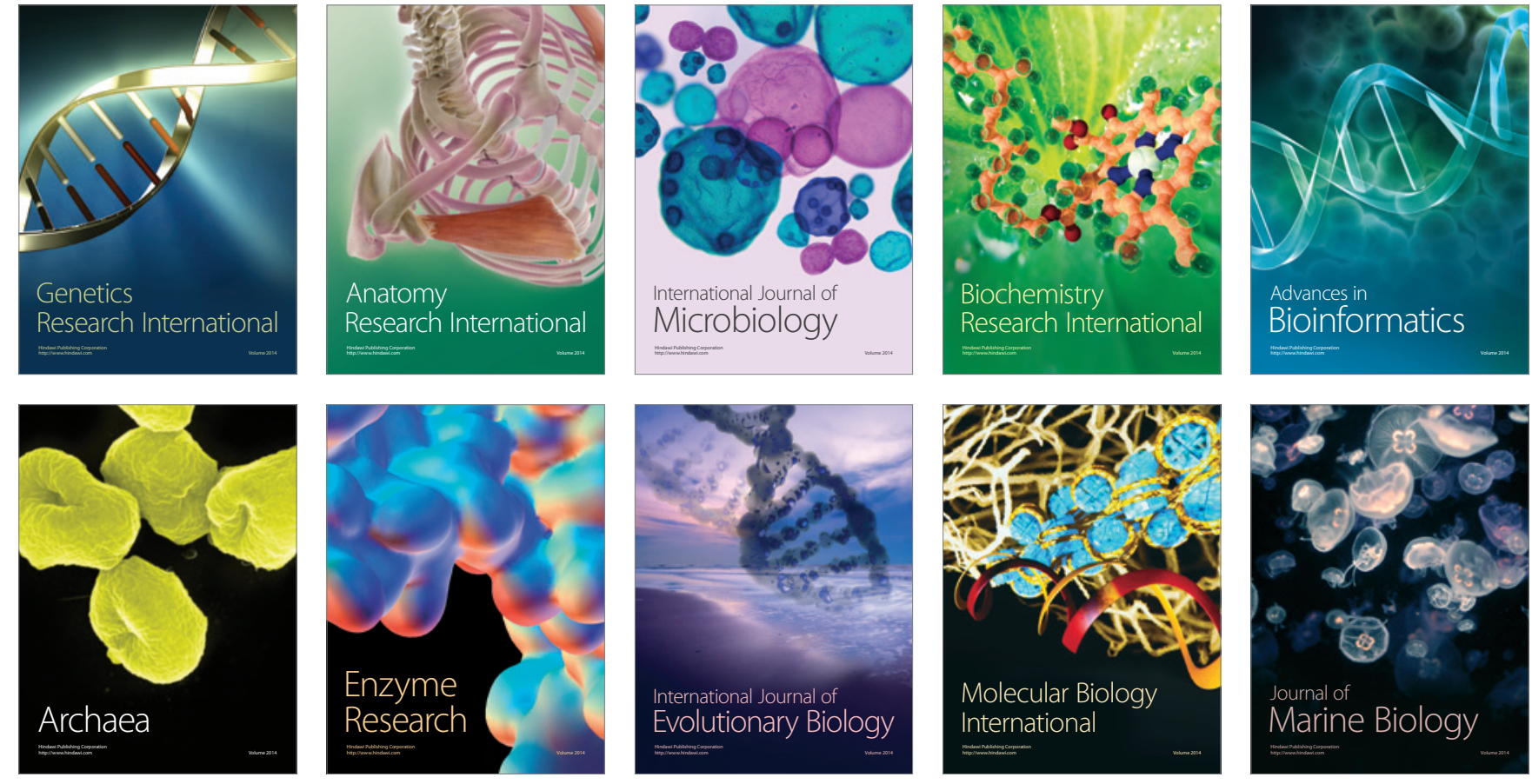